\title{
Engineered hybrid insecticidal protein improves resistance to lepidopteran insects in rice (Oryza sativa L.) and maize (Zea mays L.)
}

Yang Liu

Jilin Academy of Agricultural Sciences

Siping Han

Jilin Academy of Agricultural Sciences

Shuo Yang

Jilin University

\section{Ziqi Chen}

Jilin Academy of Agricultural Sciences

\section{Yuejia Yin}

Jilin Academy of Agricultural Sciences

Jinghui Xi

Jilin University

Qing Liu

Jilin Academy of Agricultural Sciences

\section{Xinyuan Song}

Jilin Academy of Agricultural Sciences

Fangfang Zhao

Harbin Normal University

Jia Guo

Jilin Academy of Agricultural Sciences

Xiangguo Liu

Jilin Academy of Agricultural Sciences

Dongyun Hao ( $\nabla$ dyhao@cjaas.com )

Jilin Academy of Agricultural Sciences

\section{Research Article}

Keywords: Hybrid Cry proteins, Cry1Ab/Gc, Lepidopteran insects, maize, rice

Posted Date: January 14th, 2022

DOI: https://doi.org/10.21203/rs.3.rs-1226934/v1 
License: (c) (i) This work is licensed under a Creative Commons Attribution 4.0 International License. Read Full License 


\section{Abstract}

Though cry gene transformed crops have successfully revolutionized modern agriculture, it is still necessary to discover new Cry proteins to overcome potential threatens from the development of resistant insect populations. We swapped domain-Ills with various Cry proteins and engineered seven chimeric proteins, aiming to produce new engineered hybrid insecticidal proteins. Seven recombinant proteins were expressed in Escherichia coli. Three proteins exhibited high toxicity against Asian corn borer in dietary exposure assays. Three hybrid proteins were further transformed to rice (cv. Jijing88) to determine their insecticidal activity. Cry $1 \mathrm{Ab} / \mathrm{Gc}$ hybrid proteins, Cry $1 \mathrm{Ab}$ being replaced by the domain-III of Cry $1 \mathrm{Gc}$, showed significantly more toxic against rice stem borer than others. Furthermore, $\mathrm{Cry} 1 \mathrm{Ab} / \mathrm{Gc}$ gene was transformed into maize (cv. Hill), then backcrossed into commercial maize inbred lines (cv. Ji853 and Y822), and formulated into Xiangyu 998 hybrid to evaluate their commercial value. Transgenic maize performed significant resistance improvement to the Asian corn borer without affecting the yield, and this new protein did not have adverse effects on the environment. Our result proved domain-swapped could be used as an efficient method for exploring new cry genes and engineered hybrid insecticidal protein. Cry $1 \mathrm{Ab} / \mathrm{Gc}$ provides a new tool for Lepidopteran insects resistant management in rice and maize.

\section{Introduction}

Lepidopteran plant pests are a major factor in the yield loss of important crops ${ }^{[1-4]}$. The development of genetically modified crops expressing genes derived from Bacillus thuringiensis (BT) that encode insecticidal crystalline (Cry) proteins has proven to be effective in controlling these insects ${ }^{[5,6]}$. Many Cryexpressing varieties have been successfully commercialized to date, such as Bollgard II (expressing Cry1Ac and Cry2Ab) in cotton ${ }^{[7]}$ and Genuity-SmartStax (expressing Cry1A.105, Cry1F, Cry2Ab, Cry34Ab, and Cry35Ab) in maize ${ }^{[8]}$. The commercialization of insect-resistant crops leads to increasing concern that insect populations are very likely to develop resistance to insecticidal proteins from these crops. Several methods have been suggested for the prevention of this problem. One is using high-dose Cry proteins in combination with a refuge ${ }^{[9]}$; another is mixing different toxins in one crop ${ }^{[10]}$. Exploring new insect-resistance proteins is another important approach to address emerging resistance ${ }^{[11-16]}$.

Cry toxins have been isolated from the natural environment, using traditional strategies of strain screening and molecular cloning. Based on sequence homology and insecticidal specificity, crystal proteins have been categorized into 68 main groups. In previous studies, the action mode of crystal proteins has been elucidated. Most Cry family proteins are considered to be composed of two distinct structural fragments, $\mathrm{N}$-terminal and $\mathrm{C}$-terminal. $\mathrm{N}$-terminal is highly conserved and functions in toxicity, and $\mathrm{C}$-terminal mainly acts to maintain the correct conformation of proteins ${ }^{[17]}$. Some evidence has supported that only overexpressing $\mathrm{N}$-terminal fragments could provide efficient insect-resistance in transgenic crops, such as MON810 (Monsanto) ${ }^{[8]}$. Different subfamilies of Cry proteins have been proved to have different spectra of activities on various insect targets, dependent on their diverse Amino acids in $\mathrm{N}$-terminal fragments ${ }^{[18,19]}$. In N-terminal fragment of most Cry proteins, three key domains were 
identified. Domain I is composed of seven antiparallel a-helices and is involved in membrane pore formation. Domain II is composed of three beta-laminates and participates in the specific binding of intestinal receptors ${ }^{[20]}$. Domain III has a beta-sandwich structure, together with domain II, is responsible for structural stability and interaction with insect receptors ${ }^{[21]}$. Active toxins bind receptors at the brush border membrane of mid-gut insect cells, inducing pore formation and cell death.

Engineered domain-Ills of Cry proteins have been suggested as promising tool strategies for the development and exploration of new insecticidal proteins ${ }^{[22]}$. The most famous case is Cry $1 \mathrm{~A} .105$, which has been successfully used in commercial transgenic event Mon89034 (Monsanto). Cry1A.105 protein, which was constructed by domain I and domain II of Cry $1 \mathrm{Ab}$, domain III of Cry1F, and the $\mathrm{C}$ - terminal of Cry1Ac, improves the insecticidal effects against lepidopteran insects, especially fall armyworm ${ }^{[23]}$. Moreover, when domain III of Cry $1 \mathrm{Ab}$ is substituted with domain III of Cry $1 \mathrm{C}$, the variant Cry $1 \mathrm{Ab}$ toxin exhibits a six-fold enhancement of its activity against Spodoptera exigua compared with $\mathrm{Cry} 1 \mathrm{C}^{[24]}$. Similarly, the exchange of domain III of Cry1la with that of Cry1Ba results in a toxin exhibiting a sevenfold increase in the activity against the Coleopteran Leptinotarsa decemlineata compared with Cry $1 \mathrm{Ba}^{[25]}$. Cry $1 \mathrm{Ab}$ is toxic to Lepidopteran insects, and introduction of its domain III into Cry3Aa toxin provides effective in vitro activity against Diabrotica virgifera (Coleoptera: Chrysomelidae) ${ }^{[26,27]}$.

In this report, we examined 19 representative Cry proteins and analyzed their genetic relationships in a phylogenetic tree. Then we generated seven artificial Cry proteins by domain-swapping: we used Cry $1 \mathrm{Ab}^{[23]}$, the widely and commercially applied protein, as the domain I and II donors, and seven proteins from different subfamilies as domain III donors. These Cry proteins were expressed in E. coli, and we performed dietary exposure assays to assess their toxicity to insect pests. Our results showed that three of the artificial hybrid Cry proteins had high toxicity to Asian corn borer in both dietary exposure assay and transgenic rice. Furthermore, we selected the most toxic protein, $\mathrm{Cry} 1 \mathrm{Ab} / \mathrm{Gc}$ to analyze its ability to confer insect resistance, to assess its ecological risks, and to explore its potential commercial breeding value in maize.

\section{Results}

\section{Design and synthesis of novel Cry proteins.}

We obtained 19 Cry protein sequences from NationalCenter for Biotechnology Information (NCBI) database and analyzed their genetic relationship using DNAMAN software. Our phylogenetic analysis of Cry toxins indicated that the branch formed by Cry1 toxins was clearly and sufficiently separated from other toxins, classifying Cry 1 toxins as a subdivision group in the phylogenetic tree (Fig. 1A). Moreover, Cry 9 and Cry 2 toxin groups were not located in Cry 1 branch, but Cry 9 toxins were more closely related to Cry1 toxins (Fig. 1A).

Seven representative Cry proteins, Cry1Ac, Cry1Ba, Cry1Gc, Cry1la, Cry1Jb, Cry2Ae, and Cry9Ca, were selected according to their amino acid sequence similarities that decided their phylogenetic relationships. 
Seven new three-domain constructs were made by swapping domain III of the Cry $1 \mathrm{Ab}$ protein for domain III of each selected Cry protein (Fig. 1B), and they were named based on domain III fusion; for example, Cry $1 \mathrm{Ab}-1 \mathrm{Gc}$ has domains I and II from Cry1 Ab and domain III from Cry1Gc.

\section{Testing Hybrid Proteins for Insecticidal Activity by Dietary exposure assay.}

To test the insecticidal activity of these hybrid proteins, we performed laboratory bioassays, using a diet incorporation method ${ }^{[28]}$. Results of the bioassays are illustrated in Fig. 1C, D. The column indicates relative levels of Asian corn borer activity. In the current study, the engineered hybrid Cry proteins displayed diverse toxicity to Asian corn borer larvae. Cry1 Ab-1 Jb and Cry1 Ab-2Ae produced lower activities against Asian corn borer, resulting in lower mortality rates than others (Fig. 1D). Similar to Cry1Ab, Cry1Ab-1Gc, Cry1Ab-1Ac and Cry1Ab-1la showed higher toxicity against Asian corn borer than others (Fig. 1D). Insect mortality was the greatest on diets containing Cry1Ab-1Gc or Cry1Ab (Fig. 1C). These results indicated that Cry $1 \mathrm{Ab}-1 \mathrm{Gc}$ had considerably similar toxicity to Asian corn borer by substituting Cry $1 \mathrm{Ab}$ 's domain III with that of Cry $1 \mathrm{Gc}$.

\section{Expression and insect resistance analysis of Cry1Ab-1Gc, Cry1Ab-1Ac, and Cry1Ab-1la in transgenic rice.}

Cry1Ab, Cry1Ab/1Gc, Cry1Ab/1Ac, and Cry1Ab/1 la were transformed to rice (cv. Jijing88) to determine their insecticidal activity in plants. To improve expression in plants, coding sequence (CDS) of engineered hybrid insecticidal protein was optimized codon usage for plant-preference, and ZmUbi promoter was used to effectively drive transgenic constitutive expression in monocot plants ${ }^{[29]}$ (Supplementary Fig. 1). $11 \mathrm{cry} 1 \mathrm{Ab} / \mathrm{Gc}, 15 \mathrm{cry} 1 \mathrm{Ab} / \mathrm{Ac}, 21 \mathrm{cry} 1 \mathrm{Ab} / \mathrm{la}$ independent over-expression events were obtained. The insect bioassay in the greenhouse showed that larvae of the rice stem borer were killed, and no bite holes were visible in the transgenic stems (Supplementary Fig. 2). The average mortality rate of rice stem borer feeding on transgenic rice was significantly higher than that of the control rice line (cv. Jijing88) (Supplementary Tab. S1). All the transgenic rice showed significant enhancement rice stem borer resistance, for instance, $\mathrm{Cry} 1 \mathrm{Ab} / \mathrm{Gc}$-over-expression rice, which has the highest insecticidal activity to rice stem borer (Supplementary Fig. 2).

ELISA data showed that $\mathrm{Cry} 1 \mathrm{Ab} / 1 \mathrm{Gc}$ protein was present in three independent transgenic events, and $\mathrm{C}-3$ event had higher Cry $1 \mathrm{Ab} / 1 \mathrm{Gc}$ protein content (Fig. 2A). All transgenic events had no obvious damage symptoms, the control rice showed dead sheaths, withered white particles, and a greater number of tillers with damaged borders. Fig. 2B, Fig. 2C and Tab. 1 displayed the result of insect resistance assessment of representative $\mathrm{C}-3$ line. The damaged tiller rate (number of tillers damaged/total tillers) in the transgenic rice was $3.95 \%$, which was substantially lower than that observed in the control rice (46.15\%). These results show that transgenic rice expressing the $\mathrm{Cry} 1 \mathrm{Ab} / 1 \mathrm{Gc}$ toxin exhibited higher resistance against lepidopteran insects. 
Table 1

Insect resistance assay of the transgenic rice in the greenhouse

\begin{tabular}{|lllll|}
\hline Rice lines & No. of plants & Total tillers & No. of tillers damaged & Damaged tiller rate (\%) \\
\hline CK & 45 & 832 & 384 & $46.15 \pm 4.31^{\star \star}$ \\
\hline C-3 & 45 & 810 & 32 & $3.95 \pm 0.44$ \\
\hline $\begin{array}{l}\text { Note: Means }( \pm S E) \\
\text { 0.01). }\end{array}$ & & & \\
\hline
\end{tabular}

\section{Insect resistance assay of $c r y 1 \mathrm{Ab} / 1 \mathrm{Gc}$ in transgenic maize.}

To further analyze commercialization of Cry $1 \mathrm{Ab} / 1 \mathrm{Gc}$, the plant expression vector pTF101.1-pZmUbicry $1 \mathrm{Ab} / 1 \mathrm{Gc}$ was transferred into maize (cv. Hill) by Agrobacterium-mediated transformation. We selected three transgenic events (HG-1, HG-2, and HG-3) for assessment. ELISA data showed that HG-1 event had higher Cry $1 \mathrm{Ab} / 1 \mathrm{Gc}$ protein content than others on the leaf, root, and stem (Fig. 3A).

The number of borers, the length of borer tunnels, and the number of surviving larvae were recorded at the silking stage in a function identification pool. The result showed that three transgenic events had good insect resistance. Event HG-1 was the best one, the number of borers in transgenic maize HG-1 was fewer, the length of tunnels was shorter (Fig. $3 \mathrm{C}$ and Tab.2). There were almost no live insects, but there were more live borers in non-transgenic maize, and a significant difference between them was found (Supplementary Tab. S2). As illustrated in Fig. 3B, event HG-1 had good resistance, as little filaments were fed, and the corn borer was dead after receiving transgenic maize filament in a laboratory bioassay.

(A) ELISA of Cry $1 \mathrm{Ab} / 1 \mathrm{Gc}$ protein in three transgenic lines. (B) Insect resistance performance of maize filament in laboratory. (C) Insect resistance performance of maize in field. Scale bar, $10 \mathrm{~cm}$

Table 2

Insect resistance of transgenic inbred lines against Asian corn borer

\begin{tabular}{|lllll|}
\hline Maize lines & No. of plants & No. of channels & Length of tunnel $(\mathbf{c m})$ & No. of live larvae \\
\hline CK & 12 & $2.92 \pm 0.62$ & $4.75 \pm 1.23$ & $0.75 \pm 0.25$ \\
\hline HG- & 14 & $0.36 \pm 0.17^{* \star}$ & $1.36 \pm 1.00^{* \star}$ & $0.00 \pm 0.00^{* \star}$ \\
\hline $\begin{array}{l}\text { Note: Means }( \pm \text { SE) within a column followed by different letters are significantly different }(t \text {-test, } \\
\text { 0.01). }\end{array}$ & & \\
\hline
\end{tabular}

To Further evaluate the application value of cry $1 \mathrm{Ab} / \mathrm{Gc}$, event HG-1 was backcrossed to local commercial inbred line Y822 and Ji853. In the field, the Asian corn borer caused no visible damage to transgenic inbred lines. However, the control plants infested by Asian corn borer showed significantly greater numbers of holes and longer tunnels (Tab. 3). Our results reveal that cry $1 \mathrm{Ab} / \mathrm{Gc}$ transgenic maize has 
higher resistance to Asian corn borer than non-transgenic maize plants. Further more, three independent baccross inbred line of $\mathrm{Y}_{822_{\mathrm{HG}-1}}$ were seclted as the female parents, and cross with the male parent X923-1 to product the hybrid seed Xiangyu998 ${ }_{\mathrm{HG}-1}$. The field test results show that there was no significant difference in yield traits (Fig. 4).

Considering that cry $1 \mathrm{Ab} / \mathrm{Gc}$ is a new BT protein, we then performed an environmental impact to evaluate and analyze in the field. In order to further clarify whether genetically modified corn is harmful to the environment, population dynamics and biodiversity of the non-target arthropod (a representative environmental indicator) were investigated and analyzed by direct observation and pitfall traps. Temporal variation of biodiversity in one year supported that there were no significant differences between cry $1 \mathrm{Ab} / \mathrm{Gc}$ maize and the non-BT maize field in the total number of individuals of the dominant arthropod species, the Shannon index $(\mathrm{H})$, Pielou index (J), and Simpson index (D) (Supplementary Fig. 3). Field tests also show that cry $1 \mathrm{Ab} / \mathrm{Gc}$ has no significant negative impact on the population dynamics of arthropod community (Supplementary Fig. 4-5), suggesting that this new engineered hybrid insecticidal protein cry $1 \mathrm{Ab} / \mathrm{Gc}$ hold no significant impact on ecology.

Table 3

Insect resistance of transgenic inbred lines (cv. Ji853 ${ }^{C r y} 1 A b / G C$ and Y $822^{C r y 1 A b / G c}$ ) against Asian corn borer

\begin{tabular}{|c|c|c|c|c|}
\hline Maize lines & No. of plants & No. of channels & Length of tunnel $(\mathrm{cm})$ & No. of live larvae \\
\hline Ji853 & 13 & $1.15 \pm 0.27$ & $2.77 \pm 0.90$ & $0.23 \pm 0.17$ \\
\hline Ji853 $c r y 1 A b / G c$ & 24 & $0.25 \pm 0.09^{* *}$ & $0.35 \pm 0.25^{* *}$ & $0.08 \pm 0.06^{*}$ \\
\hline Y822 & 13 & $2.46 \pm 0.55$ & $5.00 \pm 1.40$ & $0.54 \pm 0.27$ \\
\hline Y822 $c r y 1 A b / G c$ & 12 & $0.58 \pm 0.19^{\star *}$ & $1.00 \pm 0.44^{\star \star}$ & $0.08 \pm 0.08^{\star \star}$ \\
\hline
\end{tabular}

\section{Discussion}

Insects resistant to Cry proteins have developed in the field, which has successfully revolutionized modern agriculture. Cry proteins vary in their toxicity to different insects, and determine such differences can inform efforts to produce transgenic insect-resistant crops. Insects can distinguish and preferentially feed on diets containing different Cry proteins ${ }^{[30,31]}$. Cry proteins have a diversity of insecticidal activities to different lepidopteran insects, including Earias insulana (Lepidoptera: Noctuidae), Lobesia botrana (Lepidoptera: Tortricidae) ${ }^{[32]}$, Chilo suppressalis (Lepidoptera: Pyralididae) ${ }^{[19]}$, Cnaphalocrocis medinalis (Lepidoptera: Pyralidae) ${ }^{[33]}$. 
To protect the long-term utility of BT technology of pest control, it is necessary to develop new high potency Cry proteins. In this study, we selected seven distantly related Cry proteins and constructed seven novel domain mutants by swapping domain III of Cry $1 \mathrm{Ab}$ with seven related proteins. We then used dietary exposure assays to characterize the toxicity of new mutant Cry proteins to Asian corn borer (Lepidoptera: Pyralididae), resulting in the following ranking: Cry1Ab-1Gc $\geqq$ Cry $1 \mathrm{Ab}>\mathrm{Cry} 1 \mathrm{Ab}-1 \mathrm{la}>$ Cry1Ab-1Ac $>$ Cry 1 Ab-9Ca $>$ Cry1Ab-1Ba $>$ Cry1Ab-2Ae $>$ Cry1Ab-1 Jb $>$ pET28a. Similar to previous studies, our results revealed Cry $1 \mathrm{Ab} / \mathrm{Gc}$ hybrid proteins produced by domain-swap could provide diverse insecticidal activities. Yang et.al found Cry1 A/Cry1/-like fusion protein expressed in transgenic rice is effective at controlling lepidopteran pests ${ }^{[34]}$. We also found engineered hybrid Cry $1 \mathrm{Ab}$ and Cry $11 \mathrm{la}$ could provide new insecticidal proteins for pest management in rice. Cry $1 \mathrm{Gc}$, also named CryET66, showed insecticidal activities against the European corn borer, but its toxicity was lower than that of Cry $1 \mathrm{Ab}^{[35]}$. Interestingly, according to our results, the exchange of domain III of Cry $1 \mathrm{Gc}$ with Cry $1 \mathrm{Ab}$ improved Cry1Gc's resistance to the Asian corn borer, demonstrating similar insecticidal activities with Cry $1 \mathrm{Ab}$. Therefore, we believe that the combination of domain I and II of Cry1Ab and domain III of Cry1Gc may increase the stability of expression proteins, thereby enhancing insect resistance. In addition, the recognition of Cry toxins by cell surface receptors has been proven to occur in different domain III regions $^{[36-39]}$. Cry $1 \mathrm{Ab}$ and $\mathrm{Cry} 1 \mathrm{Gc}$ shared $53.96 \%$ identity in domain III. It has higher insecticidal activity than Cry1Ab protein to Plutella xylostella (Lepidoptera: Plutellidae) ${ }^{35}$. Therefore, Cry1Ab-1Gc Engineered hybrid insecticidal proteins may exhibit a broader insecticidal spectrum. In the future, we aim to explore whether protein confers resistance to other insects, its cross-resistance, and its specific insect binding site. The relationship of these residues with insect resistance will be evaluation require further examination of 3D protein structure and anti-insect mechanism via in silico analyses ${ }^{[40]}$.

Cry $1 \mathrm{Ab} / 1 \mathrm{Gc}$ was selected for more intensive studies in crops. Rice is one of the most important crops in the world and a model monocot system. Insect resistance bioassays in a greenhouse demonstrated that the transgenic rice created in the current study was highly resistant to rice stem borer. In addition, Asian corn borer seriously affected the quality and yield of spring maize in Northeast China ${ }^{[41]}$. Jidan209 and Xiangyu 998 are commercial maize hybrids with high yields and disease resistance, but susceptible to damage from insects. In our study, Cry $1 \mathrm{Ab} / 1 \mathrm{Gc}$ over-expression event was backcrossed and transferred to Ji853 (female parent of Jidan209) and Y822 (female parent of xiangyu998). Field bioassays indicated that Cry $1 \mathrm{Ab} / \mathrm{Gc}$ can significantly confer sufficient resistance to Asian corn borer in maize commercial inbred line. Using Y822 as the female parent and X923-1 as the male parent, three transgenic hybrid combinations were prepared, and the yield of the transgenic hybrid combination and the commercial variety Xiangyu 998 was tested. The results showed that the transgenic Cry $1 \mathrm{Ab} / 1 \mathrm{Gc}$ gene hybrid combination conferred insect resistance to maize, But the weight per ear is not significantly different from Xiangyu 998. Our study provides a new report of insect resistance produced by the expression of a novel engineered hybrid insecticidal protein in both rice and different maize inbreds line in China.

Furthermore, although BT crops have been commercially planted in a large number of countries, their safety for environment is still controversial ${ }^{[42]}$. However, this safety of new BT protein is the key to 
commercial application. In this study, the new engineered hybrid insecticidal protein cry $1 \mathrm{Ab} / \mathrm{Gc}$ was performed the ecological risk assessment in transgenic maize with one-year field investigation by diverse methods. We selected non-target arthropods as an important environmental indicator based on their sufficient abundance, low mobility, and clear path of exposure ${ }^{[43]}$. Our results showed the cry $1 \mathrm{Ab} / \mathrm{Gc}-$ over-expression maize had no significantly negative impacts on arthropod diversity in the field. This result was consistent with previous studies, which proved that BT maize include Cry $1 \mathrm{Ab}^{[44]}, \mathrm{Cry} 1 \mathrm{Ac}{ }^{[45,46]}$ and $\mathrm{Cry}_{3 \mathrm{Bb}}{ }^{[47]}$ did not affect the population dynamics and biodiversity of the non-target insect. Notably, in this study, we only conducted one-year research, so continuous and systematic research would be helpful to confirm the environmental safety of cry $1 \mathrm{Ab} / \mathrm{Gc}$ protein release.

\section{Conclusion}

In summary, we constructed seven new Cry proteins by a domain-swapping strategy. Dietary exposure assay yielded three highly active insect-resistant proteins, Cry $1 \mathrm{Ab}-1 \mathrm{Gc}$, Cry $1 \mathrm{Ab}-1 \mathrm{Ac}$ and Cry $1 \mathrm{Ab}-1 \mathrm{la}$. The transgenic maize and rice plants expressing $\mathrm{Cry} 1 \mathrm{Ab} / \mathrm{Gc}$ were highly resistant to two lepidopteran insects, rice stem borer and Asian corn borer. The result of ecological risk assessments suggests the release of cry $1 \mathrm{Ab} / \mathrm{Gc}$ protein is environmentally safe. The current study has supported the domain swapping method as a useful tool for the development and exploration of new Cry proteins, and revealed Cry $1 \mathrm{Ab} / \mathrm{Gc}$ would provide new tools for managing insect pests in both maize and rice.

\section{Methods}

Insects.

Neonates of Asian corn borer (Ostrinia furnacalis)and Rice stem borer (Chilo suppressalis) used in this study were obtained from the General Pest Company (Beijing, China) and were kept in a climatecontrolled chamber at $26 \pm h^{\circ} \mathrm{C}, 70 \pm 7 \mathrm{mber}$ at $2 \mathrm{~s}$ study were obtained from the General6:8 (L: D) $\mathrm{h}$ at Agrobiotechnology Research Institute, Jilin Academy of Agricultural Sciences, China.

\section{Design and synthesis of novel Cry proteins.}

The different Cry protein sequences, Cry1Ab1 (https://www.ncbi.nlm.nih.gov/protein/AEV45790.1), Cry1Ab5 (https://www.ncbi.nlm.nih.gov/protein/CAA28405.1), Cry1Ab14

(https://www.ncbi.nlm.nih.gov/protein/AAG16877), Cry1Ac (https://www.ncbi.nlm.nih.gov/protein/WP_000369821.1), Cry1Ah

(https://www.ncbi.nlm.nih.gov/protein/AAQ14326.1), Cry1Ba (https://www.ncbi.nlm.nih.gov/protein/WP_000203376.1/), Cry1Be (https://www.ncbi.nlm.nih.gov/protein/085805.1), Cry1Bb (https://www.ncbi.nlm.nih.gov/protein/WP_000203375.1), Cry1la (https://www.ncbi.nlm.nih.gov/protein/CAA44633.1), Cry1Fa (https://www.ncbi.nlm.nih.gov/protein/Q03746.1), Cry1Ja 
(https://www.ncbi.nlm.nih.gov/protein/WP_098369107.1), Cry1Jb

(https://www.ncbi.nlm.nih.gov/protein/Q45716.1), Cry9Aa

(https://www.ncbi.nlm.nih.gov/protein/WP_087997148.1), Cry9Ca

(https://www.ncbi.nlm.nih.gov/protein/Q45733.1), Cry9Ec

(https://www.ncbi.nlm.nih.gov/protein/AAS68357.1), Cry2Ab

(https://www.ncbi.nlm.nih.gov/protein/WP_001089638.1), Cry2Ae

(https://www.ncbi.nlm.nih.gov/protein/ABW49930.1), Cry2Ac

(https://www.ncbi.nlm.nih.gov/protein/Q45743.1), Cry1Gc ${ }^{[35]}$ were obtained from the National Center for Biotechnology Information (NCBI) database, and the genetic relationships were analyzed using DNAMAN software (Version 6). Construct domain mutants were created by swapping domain III of seven distantly related proteins for domain III of Cry1Ab protein. The selected new proteins were synthesized and expressed in Escherichia coli by Sheng Gong Company (China).

\section{Dietary exposure screen.}

E. coli clones that express seven Cry proteins, Cry1Ab-1Gc, Cry1Ab-1la, Cry1Ab-1Ac, Cry1Ab-9Ca, Cry1Ab$1 \mathrm{Ba}, \mathrm{Cry} 1 \mathrm{Ab}-2 \mathrm{Ae}$, and Cry1 Ab-1 Jb were grown overnight. The expression vector $\mathrm{pET} 28 \mathrm{a}$ without $\mathrm{Cry}$ protein was used as the negative control. $5 \mathrm{ml}$ overnight culture was sonicated and the amount of protein to be tested. Stock solutions of the seven Cry proteins were diluted with distilled water and incorporated into an artificial diet for Asian corn borer to the same concentration, $100 \mu \mathrm{g} / \mathrm{ml}$. Since the Asian corn borer diet must be heated during preparation, the Cry protein solutions were mixed into the diet when its temperature had decreased to $<60^{\circ} \mathrm{C}$ to avoid degradation. Once the food was solid, it was cut into slices and individually placed in $10 \mathrm{~cm}$ diameter Petri dishes. Ten neonates of Asian corn borer were transferred into each Petri dish, which was then sealed with breathable film to prevent the larvae from escaping. The feeding assay was conducted in a growth chamber at $28^{\circ} \mathrm{C}, 80 \%$ relative humidity, and a $12 \mathrm{~h}$ photoperiod. Three replicates were used for each protein. Mortality was recorded after 5 days.

\section{Construction of over-expression vector and genetic transformation.}

Cry $1 A b-1 G c$, cry $1 A b-1 A c$, cry $1 A b-1 / a$ were expressed in Escherichia coli, and the synthetic cry gene was designed as outlined through the codon usage of rice ${ }^{[48]}$. The $p$ TF101.1-ubi vector and the plasmid containing cry genes were digested with Smal and Sacl, and two fragments were connected to the vector by T4 DNA ligase (Thermo Fisher Scientific, USA).

To test the toxicity of the new protein against insects in monocot crops, cry $1 \mathrm{Ab} / \mathrm{Gc}] \mathrm{cry} 1 \mathrm{Ab} / \mathrm{Ac} \nabla c r y 1 \mathrm{Ab} / \mathrm{la}$ were transformed into rice (cv. Jijing 88) using Agrobacterium-mediated genetic transformation with the above vector, respectively. The same method was used to transform cry $1 A b / G c$ into maize (cv. Hill).

\section{Enzyme-linked immunosorbent assay (ELISA).}

The expression of Cry $1 \mathrm{Ab} / \mathrm{Gc}$ protein in transgenic plants was quantitatively analyzed by Enzyme-linked immunosorbent assay (ELISA) using the Cry1Ab/Cry1Ac plate kit (Agida, USA) according to its 
instructions. Leaves of transgenic rice at the tillering stage were ground into powder using liquid nitrogen, and $0.02 \mathrm{~g}$ powder was weighed into $1.5 \mathrm{ml}$ centrifuge tubes with $500 \mu \mathrm{l}$ extraction buffer. Samples were diluted 400 -fold after mixing, and $50 \mu \mathrm{l}$ of each sample was used for detection. The non-transgenic rice (cv. Jijing 88) was used as a negative control. The standard curve was constructed using a concentration gradient $(0.02,0.016,0.012,0.008,0.004$, and $0 \mathrm{ng})$ for the quantitative analysis of samples. We selected one transgenic line (C-3) with high Cry $1 \mathrm{Ab} / \mathrm{Gc}$ protein levels for insect bioassay. The same method was used to confirm the presence of the transgene in maize.

\section{Evaluation of insect resistance of transgenic rice.}

The insect bioassay was conducted using the test tube method in the laboratory. Rice stems of these three transgenic rice with $c r y 1 A b / G c, c r y 1 A b / A c$ and $c r y 1 A b / l a$ at tillering stage were cut into $6-\mathrm{cm}$ sections. Five stem sections were each placed into separate test tubes, filled with $1 \%$ agar to a depth of 2 $\mathrm{cm}$. Ten rice stem borer larvae were released into each test tube with 5 repetitions. Test tubes were sealed with cotton balls to prevent the larvae from escaping. The feeding assay was conducted in a growth chamber at $28^{\circ} \mathrm{C}, 80 \%$ relative humidity, and 12 -h photoperiod. Damage to stem tissues and larval mortality were observed and analyzed by $t$ test after infestated for five days. Non-transgenic plants were used as a negative control. All data were analyzed by $t$-test $\left({ }^{\star} P<0.05 ; * \star P<0.01\right)$.

Transgenic rice event C-3 with $c r y 1 A b / G c$ gene was planted in a greenhouse with normal field treatment and surrounded with wild-type Jijing88 as a negative control. No pesticide was applied during the growth period. Twenty neonates of rice stem borer were placed into the hearts of tillers of every rice plant at tillering stage. Insect occupancy was observed every 12 days. Rice tiller performance and the number of tillers damaged were compared with the controlled rice by $t$-test $\left({ }^{\star} P<0.05 ;{ }^{*} P<0.01\right)$.

\section{Evaluation of insect resistance of transgenic maize.}

Cry $1 \mathrm{Ab} / \mathrm{Gc}$ was transformed into maize (cv. Hill) using Agrobacterium-mediated genetic transformation with $p$ TF101.1-ubi-cry $1 A b / G c$ vector. Twenty neonates of Asian corn borer were placed into the heart leaf of each transgenic plant and the control plant at the silking stage in a function identification pool. The insect occupancy was observed after 14 days. Agronomic performance, length of the tunnels produced by larvae, and the number of survival larvae were observed and analyzed by $t$-test $\left({ }^{\star} P<0.05 ;{ }^{\star} * P<0.01\right)$.

The best insect resistance performance line was bred by backcross breeding. To the further, Cry $1 \mathrm{Ab} / \mathrm{Gc}-$ expressing maize inbred lines cv. Ji853 and Y822 were assessed by the same method above. Agronomic performance and length of the tunnels were compared with the control by $t$-test $\left({ }^{\star} P<0.05 ; * \star P<0.01\right)$.

\section{Hybrid yield test and statistical analyses}

Xiangyu 998 is a commercial hybrid that uses Y822 as the female parent and X923-1 as the male parent. We crossed the Y822 transgenic inbred line with X923-1 to obtain Xiangyu998 transgenic hybrid combinations. We select three lines of transgenic hybrids xiangyu- $1(+)$, xiangy $u-2(+)$, xiangyu- $3(+)$, and the corresponding negative materials, xiangyu- $1(-)$,xiangyu-2(-),xiangyu-3(-). Each material plant 10 rows, 
each row plant 20 plants under natural rainfall conditions. All material plants were open pollination, and collected at maturity period. Measure the weight of each row corn ears, record the number of ears in each row, calculate the weight of each ear, and perform statistical analysis by $t$-test.

\section{Biodiversity investigation and statistical analyses}

Cry1 Ab/Gc maize and the non-BT maize (CK) were grown in the GM fields of Jilin Academy of Agricultural Sciences located in Jilin province (2020; China; E125 $\left.{ }^{\circ}, \mathrm{N} 44^{\circ}\right)$. Cry1 Ab/Gc maize was divided into two groups, spray herbicide glufosinate (F-P) and none glufosinate application (F-BP). The number of arthropods was investigated and analyzed by direct observation and pitfall traps method ${ }^{[46]}$. Six species of arthropods (Harmonia axyridis, ladybird larvae, aphids, Monolepta hieroglyphica, spiders, and Propylaea japonica) were counted and analyzed by the method of direct observation; Four species of arthropods (Teleogryllus infernalis, Earwig furficulidae, Opiliones, and Carabidae sp.4) were counted and analyazed by the method of pitfall traps. Three indices were used to analyze the dynamics of the arthropod community: Shannon index ${ }^{[49]}$, Pielou index ${ }^{[50]}$, and Simpson index ${ }^{[51]}$.

\section{Declarations}

\section{Author contributions}

Dongyun Hao and Xiangguo Liu designed and supervised this research. Yang Liu participated in genotyping and phenotyping transgenic lines, insect bioassay in maize in the field. Xiangguo Liu, Yang Liu and Ziqi Chen performed the statistical analysis and prepared the manuscript. Siping Han and Liu Qing generated transgenic maize lines. Yuejia Yin participated in dietary exposure screen and statistical analysis in rice. Shuo Yang participated in designing and expressing new Cry proteins. Fangfang Zhao, Guo Jia, Jinghui Xi, and Siping Han participated in molecular analyses of transgenic maize, insect bioassay, and biodiversity investigation. All authors read and approved the final manuscript.

\section{Acknowledgments}

The authors are thankful to all the team- and lab mates and friends who supported us during the research project and writing of the manuscript. We thank Hongxiang Seed Industry Co., Ltd. for providing maize commercial inbred line Y822 and Dr. Wenguo Liu for maize commercial inbred line Ji853.

\section{Funding}

This work was supported by Jilin Province Science and Technology Development Plan(20126027), Jilin Province Agricultural Science and Technology Innovation Project (Jilin Financial Education $₫ 2012 \bigotimes 1072$ )

\section{Conflict of Interest Statement}

The authors declare that the research was conducted in the absence of any commercial or financial relationships that could be construed as a potential conflict of interest. 


\section{Ethics approval and consent to participate}

Not applicable.

\section{Consent for publication}

Not applicable.

\section{Competing interests}

The authors declare that they have no competing interests.

\section{General declaration}

The plant collection and use was in accordance with all the relevant guidelines.

\section{References}

1. Razze, J. M. \& Mason, C. E. Dispersal behavior of neonate European corn borer (Lepidoptera: Crambidae) on Bt corn. J Econ Entomol. 105, 1214-1223 (2012).

2. Bourguet, D. et al. Becoming a species by becoming a pestorn borer (Lepidoptpests of the genus Ostrinia possibly evolved through parallel ecological speciation events. Mol Ecol. 23, 325-342 (2014).

3. Arbab, A. Spatial Distribution and Minimum Sample Size for Overwintering Larvae of the Rice Stem Borer Chilo suppressalis (Walker) in Paddy Fields. Neotrop Entomol. 43, 415-420 (2014).

4. Chen, H., Zhang, G., Zhang, Q. \& Lin, Y. Effect of transgenic Bacillus thuringiensis rice lines on mortality and feeding behavior of rice stem borers (Lepidoptera: Crambidae). J Econ Entomol. 101, 822-189 (2008).

5. He, K. L. et al. Evaluation of transgenic Bt corn for resistance to the Asian corn borer (Lepidoptera: Pyralidae). J Econ Entomol. 96, 935-940 (2003).

6. Clive, J. Commercial development of global biotechnology/genetically modified crops in 2015. China Biotechnology. 36, 1-11 (2016).

7. Gore, J., Leonard, B. R. \& Adamczyk, J. J. Bollworm (Lepidoptera: Noctuidae) survival on 'Bollgard' and 'Bollgard II' cotton flower bud and flower components. J Econ Entomol.94, 1445-1451 (2001).

8. Siebert, M. W. et al. Evaluation of corn hybrids expressing Cry1F, Cry1A.105, Cry2Ab2, Cry34Ab1/Cry35Ab1, and Cry3Bb1 against southern United States insect pests. J Econ Entomol.105, 8225-1834 (2012).

9. Tabashnik, B. E. et al. Efficacy of genetically modified Bt toxins against insects with different genetic mechanisms of resistance. Nat Biotechnol.29, 1128-1131 (2011).

10. Roush, R. T. Two-toxin strategies for management of insecticidal transgenic crops: can pyramiding succeed where pesticide mixtures have not? Philos. Trans. R. Soc. Lond. B. 353, 1777-1786 (1998). 
11. Storer, N. P. et al. Discovery and characterization of field resistance to Bt maize: Spodoptera frugiperda (Lepidoptera: Noctuidae) in Puerto Rico. J Econ Entomol. 103, 1031-1038 (2010).

12. Van Rensburg, J. B. J. First report of field resistance by stem borer, Busseola fusca (Fuller) to Bttransgenic maize. S Afr J Plant Soil. 24, 147-151 (2007).

13. Kruger, M.. Resistance to Bt maize in Busseola fusca (Lepidoptera: Noctuidae) from Vaalharts, South Africa. Environ Entomol. 40, 477-483 (2011).

14. Dhurua, S. \& Gujar, G. T. Field-evolved resistance to Bt toxin Cry1Ac in the pink bollworm, Pectinophora gossypiella (Saunders) (Lepidoptera: Gelechiidae), from India. Pest Manag Sci. 67, 898-903 (2011).

15. Gassmann, A. J., Petzold-Maxwell, J. L., Keweshan, R. S. \& Dunbar, M. W. Field-evolved resistance to Bt maize by western corn rootworm. PLoS One. 6, e22629 (2011).

16. Gassmann, A. J. Field-evolved resistance to Bt maize by western corn rootworm: predictions from the laboratory and effects in the field. J Invertebr Pathol. 110, 287-293 (2012).

17. Bietlot, H. P., Vishnubhatla, I., Carey, P.R., Pozsgay, M. \& Kaplan, H. Characterization of the cysteine residues and disulfide linkages in the Protein crystal of Baeillus thuringiensis. Bioehem J. 267, 309315 (1990).

18. Ibargutxi, M. A., Estela, A., Ferre, J. \& Caballero, P. Use of Bacillus thuringiensis toxins for control of the cotton pest Earias insulana (Boisd.) (Lepidoptera: Noctuidae). Appl Environ Microbiol. 72, 437442 (2006).

19. Jiao, Y. Y., Yang, Y., Meissle, M., Peng, Y. F. \& Li, Y.H. Comparison of susceptibility of Chilo suppressalis and Bombyx mori to five Bacillus thuringiensis proteins. J Invertebr Pathol. 136, 95-99 (2016).

20. Dean, D. H. et al. Probing the mechanism of action of Bacillus thuringiensis insecticidal proteins by site-directed mutagenesis-A minireview. Gene. 179, 111-117 (1996).

21. Derbyshire, D. J., Ellar, D. J. \& Li, J. Crystallization of the Bacillus thuringiensis toxin Cry1Ac and its complex with the receptor ligand N-acetyl-D-galactosamine. Acta Crystallogr D Biol Crystallogr. 57, 1938-1944 (2001).

22. Deist, B. R., Rausch, M. A., Fernandez-Luna, M. T., Adang, M. J., Bonning, B. C. Bt toxin modification for enhanced efficacy. Toxins (Basel). 6, 3005-3027 (2014).

23. Anderson, H. M. et al. Corn plant and seed corresponding to transgenic event Mon89034 and methods for detection and use thereof. Patent No.:US 8581047B2 (2013).

24. De Maagd, R. A., Weemen-Hendriks, M., Siekema, W. \& Bosch, D. Bacillus thuringiensis delta-enotoxin Cry $1 \mathrm{C}$ domain III can function as a specificity determinant for Spodoptera exigua in different, but not all, Cry1-Cry1C hybrids. Appl Environ. Microbiol. 66, 1559-1563 (2000).

25. Naimov, S., Weemen-Hendriks, M., Dukiandjiev, S. \& de Maagd, R.A. Bacillus thuringiensis $\delta$-endotoxin Cry 1 hybrid proteins with increased activity against the Colorado potato beetle. App/ Environ Microbiol. 67, 5328-5330 (2001). 
26. Walters, F. S., deFontes, C. M., Hart, H., Warren, G. \& Chen, J. Lepidopteran-active variable-region sequence imparts coleopteran activity in eCry3.1 Ab, an engineered Bacillus thuringiensis hybrid insecticidal protein. Appl Environ Microbiol. 76, 3082-3088 (2010).

27. Hibbard, B. E. et al. Mortality impact of Bt transgenic maize roots expressing eCry3.1Ab, mCry3A, and eCry3.1Ab plus mCry3A on western corn rootworm larvae in the field. $J$ Econ Entomol. 104, 15841591(2011).

28. Lu, X. Y. et al. The effect of different Bt proteins on the survival rate,growth and development of cotton bollworm larvae. Journal of Biosafety, 23, 34-39 (2014).

29. Hao, D. Y. et al. New recombinant insect resistant protein, its preparation and Application. ZL 20151 0131077.7 (2017).

30. Gore, J., Adamczyk, J. J. \& Blanco, C. A. Selective feeding of tobacco budworm and bollworm (Lepidoptera: Noctuidae) on meridic diet with different concentrations of Bacillus thuringiensis proteins. J Econ Entomol. 98, 88-94 (2005).

31. Chen, R. Z. et al. Mating Disruption or Mass Trapping, Compared With Chemical Insecticides, for Suppression of Chilo suppressalis (Lepidoptera: Crambidae) in Northeastern China. J Econ Entomol.107, 8228-1838 (2014).

32. de Escudero, I. R., Estela, A., Escriche, B. \& Caballero, P.. Potential of the Bacillus thuringiensis toxin reservoir for the control of Lobesia botrana (Lepidoptera: Tortricidae), a major pest of grape plants. Appl Environ Microbiol. 73, 337-340 (2007).

33. Yang, Y., Xu, H., Zheng, X. \& Lu, Z. Susceptibility and selectivity of Cnaphalocrocis medinalis (Lepidoptera: Pyralidae) to different cry toxins. J Econ Entomol. 105, 2122-2128(2012).

34. Yang, Y. Y., Mei, F., Zhang, W., Shen, Z. \& Fang, J. Creation of Bt rice expressing a fusion protein of Cry1Ac and Cry1-like using a green tissue-specific promoter. J Econ Entomol. 107, 1674-1679 (2014).

35. Baum, J. A., Chu, C. R., Donovan, W. P., Gilmer, A. J. \& Rupar, M. J. Bacillus thuringiensis delta endotoxin composition active to lepidopteran insects and use method thereof. . Application Patent No.: CN00815677.8 (2000).

36. Arenas, I., Bravo, A., Soberon, M. \& Gomez, I. Role of alkaline phosphatase from Manduca sexta in the mechanism of action of Bacillus thuringiensis Cry1Ab toxin. J Biol Chem. 285, 12497-12503 (2010).

37. Pacheco, S. et al. Domain II loop 3 of Bacillus thuringiensis Cry1Ab toxin is involved in a "ping pong" binding mechanism with Manduca sexta aminopeptidase-N and cadherin receptors. $J$ Biol Chem. 284, 32750-32757 (2009).

38. Shan, S. P. et al. A Cry 1 Ac toxin variant generated by directed evolution has enhanced toxicity against Lepidopteran insects. Curr Microbiol. 62, 358-365 (2011).

39. Feng, D. M. et al. Domain III of Bacillus thuringiensis Cry1le Toxin Plays an Important Role in Binding to Peritrophic Membrane of Asian Corn Borer. PLoS One.10, e0136430 (2015).

40. Lucena, W. A. et al. Molecular approaches to improve the insecticidal activity of Bacillus thuringiensis Cry toxins. Toxins (Basel).6, 2393-2423 (2014). 
41. Wang, A. Y., Lu, X., He, K. L. \& Zhou, D. R. Review of History, Present Situation and Prospect of the Asian Maize Borer Research in China. Journal of Shenyang Agricultural University. 31,402- 412 (2000).

42. Lucht, J. M. Public acceptance of plant biotechnology and GM crops. Viruses. 7, 4254-4281 (2015).

43. Romeis, J. et al. Deriving criteria to select arthropod species for laboratory tests to assess the ecological risks from cultivating arthropod-resistant genetically engineered crops. Chemosphere. 90 , 901-909 (2013).

44. Wolfenbarger, L. L., Naranjo, S. E., Lundgren, J. G., Bitzer, R. J. \& Watrud, L. S. Bt crop effects on functional guilds of non-target arthropods: a meta-analysis. PLoS One. 3, e2118 (2008).

45. Guo, Y. Y. et al. The cultivation of Bt corn producing Cry1Ac toxins does not adversely affect nontarget arthropods. PLoS One. 9, e114228 (2014).

46. Xing, Y. et al. The impact of Bt maize expressing the Cry1Ac protein on non-target arthropods. Environ Sci Pollut Res. 26, 5814-5819 (2019).

47. Devos, Y., Schrijver, A.D., Clercq, P. D., Kiss, J. \& Romeis, J. Bt-maize event Mon 88017 expressing Cry3Bb1 does not cause harm to non-target organisms. Transgenic Res. 21, 1191-1214 (2012).

48. Liu, Q. P. Analysis of codon usage bias and effects of sequence Patterns proximal to translation initiation and 284 termination codons on gene expression Oryza sativa. Zhejiang University. 72-73 (2005).

49. Shannon, C.E., Weaver, W. The mathematical theory of communication. University of Illinois Press. 60, 144 (1949).

50. Pielou, E. C. The measurement of diversity in different types of biological collections. J Theor Biol. 13, 131-144 (1966).

51. Simpson, E.H. Measurement of diversity. Nature. 163, 688 (1949)

\section{Figures}

\section{Figure 1}

Molecular design and insect bioassay of new Cry proteins. (A) The phylogenetic relationship among Cry proteins. (B) Domain swapping is used to develop new Cry proteins. (C) Average mortality rates of Asian corn borer feeding on different Cry proteins. Vertical bars indicate mean \pm SD (standard deviation) 5 days post-infestation. (D) The performance of Asian corn borer feeding on different Cry proteins. 
Expression and insect resistance analysis of $\mathrm{Cry} 1 \mathrm{Ab} / 1 \mathrm{Gc}$ protein in rice.

(A) ELISA of Cry $1 \mathrm{Ab} / 1 \mathrm{Gc}$ protein in three transgenic events. (B) Insect resistance performance of rice stems in the laboratory. Scale bar, $1 \mathrm{~cm}$. (C) Insect resistance performance in greenhouse.

Figure 3

Expression and insect resistance analysis of $\mathrm{Cry} 1 \mathrm{Ab} / 1 \mathrm{Gc}$ protein in maize.

(A) ELISA of Cry $1 \mathrm{Ab} / 1 \mathrm{Gc}$ protein in three transgenic lines. (B) Insect resistance performance of maize filament in laboratory. Insect resistance performance of maize in field. Scale bar, $10 \mathrm{~cm}$

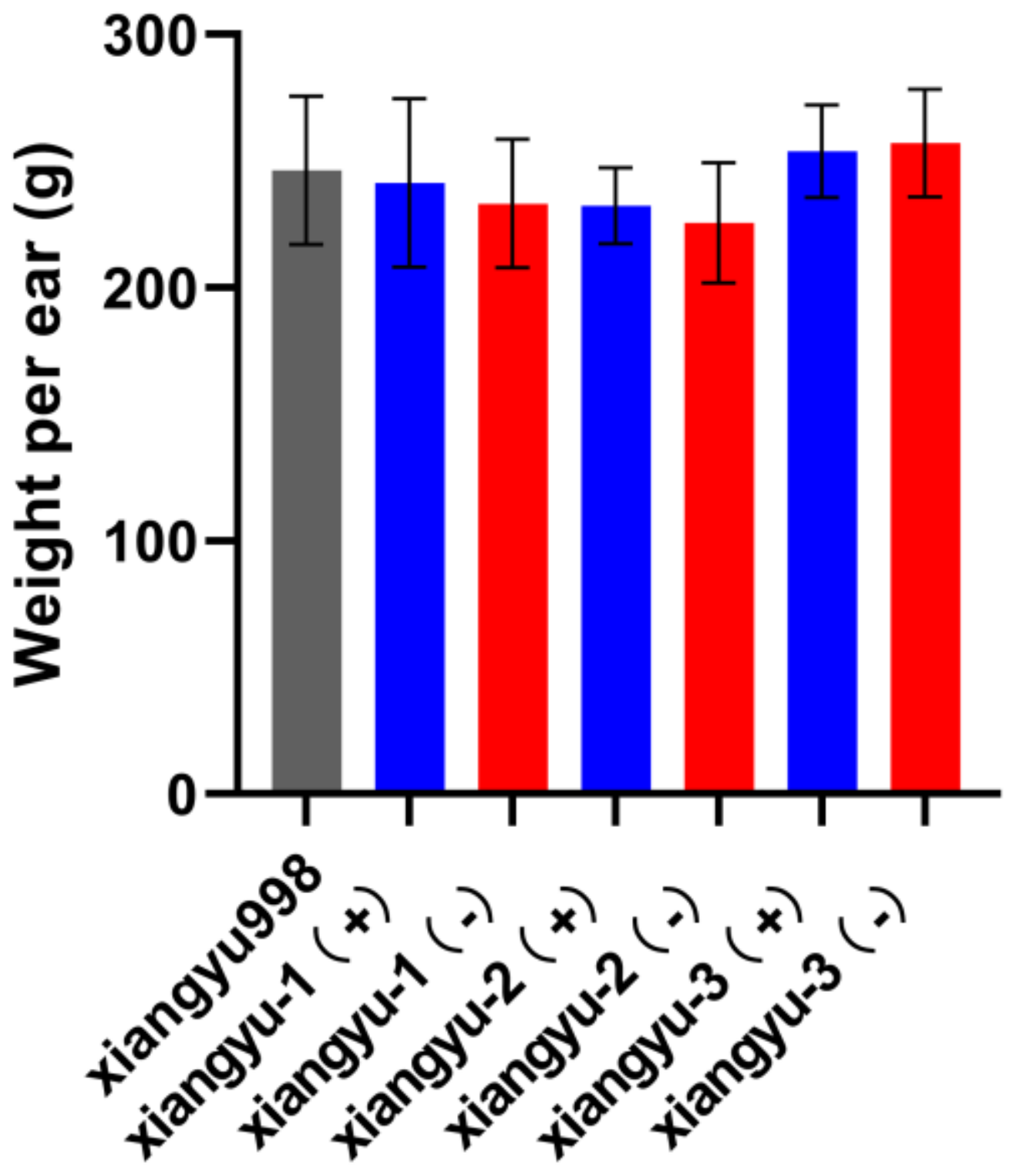




\section{Figure 4}

Weight per ear of different hybrids compared with commercial varieties. xiangyu-1(+), xiangyu-2(+), xiangyu-3(+):Transgenic hybrids; xiangyu-1(-), xiangyu-2(-), xiangyu-3(-):Transgenic hybrids: Negative separation control

\section{Supplementary Files}

This is a list of supplementary files associated with this preprint. Click to download.

- 12.251.pdf 